\title{
Expression of gelatinase B in trachomatous conjunctivitis
}

\author{
Ahmed M Abu El-Asrar, Karel Geboes, Soliman A Al-Kharashi, \\ Abdulrahman A Al-Mosallam, Luc Missotten, Liesbet Paemen, Ghislain Opdenakker
}

Department of Ophthalmology, College of Medicine, King Saud University, Riyadh, Saudi Arabia A M Abu El-Asrar S A Al-Kharashi A A Al-Mosallam

Laboratory of Histochemistry and Cytochemistry, University Hospital St Rafael, Leuven,

Belgium

K Geboes

Department of Ophthalmology L Missotten

Rega Institute for Medical Research, Laboratory of Molecular

Immunology,

University of Leuven, Leuven, Belgium

L Paemen

G Opdenakker

Correspondence to: Dr Ahmed M Abu El-Asrar, Department of

Ophthalmology, King

Abdulaziz University

Hospital, Airport Road, PO

Box 245, Riyadh 11411,

Saudi Arabia

Accepted for publication 6 September 1999

\begin{abstract}
Backgroundlaims-Gelatinase $B$ is a matrix metalloproteinase involved in extracellular matrix (ECM) breakdown often associated with scarring and other pathological disorders. It was investigated whether gelatinase $B$ is involved in the pathogenesis of ECM degradation associated with trachomatous conjunctivitis.

Methods-Conjunctival biopsy specimens obtained from six patients with active trachoma, six patients with active vernal keratoconjunctivitis (VKC), and seven control subjects were studied. Immunohistochemical techniques and a specific monoclonal antibody against human gelatinase $B$ were used, and a monoclonal antibody against macrophage CD68 to identify mononuclear cells with gelatinase $B$ immunoreactivity. In addition, quantitative zymography was used to compare the activity of gelatinase $B$ in conjunctival biopsy specimens from seven patients with active trachoma and seven control subjects.
\end{abstract}

Results-Gelatinase B was detected by immunohistochemistry only in polymorphonuclear cells located in the vascular lumens in three normal conjunctival biopsy specimens. In all trachoma specimens and in five VKC specimens, gelatinase $B$ was localised in monocytel macrophage cells, positive for the CD68 marker, and in polymorphonuclear cells. The majority of the latter cell type was located in intravascular spaces. Compared with VKC specimens, trachoma specimens showed significantly more immunoreactive gelatinase $B$ monocytel macrophage cells (52.3 (21.9) $v 8.2$ (6.4); p $<0.001)$ and polymorphonuclear cells $(23.2$ (14.2) $v 6.3(5.4) ; p=0.013)$. Activated macrophages with giant cell morphology clearly stained with the gelatinase $B$ specific monoclonal antibody were observed in trachoma specimens. Zymography revealed that gelatinase $B$ levels in trachoma specimens were significantly higher than the levels found in normal conjunctiva (1739.6 (1078.3) $v 609.3$ (395.9) scanning units; $p=0.0127)$.

Conclusions-The increased activity of gelatinase $B$ and numbers of inflammatory cells containing gelatinase $B$ in trachoma specimens suggest that this enzyme plays a part in the pathogenesis of conjunctival scarring in trachoma.

(Br f Ophthalmol 2000;84:85-91)
Trachoma is a chronic follicular keratoconjunctivitis caused by Chlamydia trachomatis serotypes $\mathrm{A}, \mathrm{B}, \mathrm{Ba}$, and $\mathrm{C} .{ }^{1}$ It remains a major worldwide cause of preventable blindness, and a major public health problem, particularly in the third world. It accounts for some $25 \%$ of world blindness, and is the commonest infectious cause of blindness. ${ }^{2}$ The blinding complications of trachoma are associated with progressive conjunctival and subconjunctival scarring that may lead to dry eye syndrome, entropion, trichiasis, and corneal blindness. The possible factors involved in chronic progressive conjunctival cicatrisation in trachoma that lead to blindness remain unclear. However, in previous immunohistochemical studies we have demonstrated that the tissue damage might result from immunological mechanisms involving $\mathrm{T}$ lymphocytes, macrophages, and cytokines released by resident conjunctival cells, and by inflammatory cells infiltrating the tissue. ${ }^{34}$ In addition, we have shown that the superficial conjunctival epithelial cells infected with $C$ trachomatis expressed major histocompatibility complex class II antigens, which may render these cells capable of acting as antigen presenting cells, thereby enhancing the immune response. ${ }^{45}$

Metabolic alterations of extracellular matrix components and collagen metabolism occur in the conjunctival tissue from patients with trachoma. ${ }^{67}$ The matrix metalloproteinases are recognised as key enzymes both for normal extracellular matrix turnover and for the exaggerated extracellular matrix breakdown associated with pathological conditions, including tumour invasion and metastasis, angiogenesis, inflammatory reactions, wound healing, and scar formation..$^{8-10}$ The major members of this family include the following: collagenases, which degrade and denature fibrillar collagen types I, II, and III; gelatinases A and B (respectively, the 65-75 kD matrix metalloproteinase- 2 and the 85-96 kD matrix metalloproteinase-9) which cleave denatured collagens (gelatins), collagen types IV, V, VII, and X, elastin, and fibronectin; and stromelysins, which degrade proteoglycans, laminin, fibronectin, type IV collagen, and the globular domains of other extracellular matrix macromolecules. ${ }^{8}$ More recently, membrane type matrix metalloproteinase expressed on cell membranes is identified as a fourth category. ${ }^{11}$

Because of its unique and broad substrate specificity, its involvement in other chronic inflammatory and autoimmune diseases, ${ }^{12}$ and its distal position in the matrix proteolytic cascade we hypothesised that excessive expression of gelatinase B may have a part in matrix degradation in trachomatous conjunctivitis. To 
test this hypothesis, we examined conjunctival specimens obtained from patients with active trachoma using immunohistochemistry and gelatin zymography. The findings in trachoma were compared with the findings in the conjunctiva from normal individuals, and from patients with vernal keratoconjunctivitis (VKC) which is a non-scarring, chronic allergic inflammation.

\section{Patients and methods}

IMMUNOHISTOCHEMISTRY

Six patients with severe active trachoma ${ }^{2}$ ranging in age from 5 to 17 years (mean age 7.7 years) were included in the study. Six patients with severe active VKC ranging in age from 7 to 15 years (mean age 10.5 years) were studied. VKC patients had the palpebral form of the disease characterised by the presence of giant polygonal flat topped cobblestone papillae affecting the upper palpebral conjunctiva. A $2 \times 2 \mathrm{~mm}$ upper palpebral conjunctival biopsy specimen was obtained from each patient after informed consent. None of the patients was on topical therapy. In addition, seven upper palpebral conjunctival biopsy specimens were obtained from patients of the same age group who underwent cataract extraction or strabismus surgery without obvious inflammation and these served as controls.

The conjunctival biopsy specimens were immediately fixed for 2-3 hours in B5 fixative composed of: (A) $90 \mathrm{ml}$ distilled water, $6 \mathrm{~g}$ mercuric chloride, 2.074 g sodium acetate; and (B) $37 \%$ formaldehyde solution, $\mathrm{pH} 5.7$. Immediately before use $9 \mathrm{ml}$ of A and $1 \mathrm{ml}$ of $\mathrm{B}$ were mixed. The specimens were then embedded in paraffin. After trypsinisation for 7 minutes at $37^{\circ} \mathrm{C}$ using a mixture of $0.1 \%$ trypsin (Sigma-Aldrich, Bornem, Belgium) and $0.1 \% \mathrm{CaCl}_{2}$ at $\mathrm{pH} 7.8$ and blocking of endogenous peroxidase activity, the sections were stained with a three step avidinperoxidase-conjugated biotin complex (ABC) method using gelatinase B specific REGA-2D9 monoclonal antibody $(1: 100)$. The mouse monoclonal antibody REGA-2D9 was raised against natural human neutrophil gelatinase B. This implies that the antigen preparation was devoid of gelatinase A. The REGA-2D9 is a IgG1 subtype with a dissociation constant (Kd) value of $9.5 \times 10-10 \mathrm{M}$, which implies extremely high specificity. ${ }^{13}$ This monoclonal antibody was compared with other antibody preparations and found to be superior for immunohistochemical analysis. ${ }^{14}$ Serial sections were stained with CD68 monoclonal antibody (1:100) to identify mononuclear/ phagocyte cells. The samples were incubated for 30 minutes at room temperature with the monoclonal antibodies. The secondary and tertiary antibodies consisted of biotin conjugated rabbit anti-mouse immunoglobulin and the avidin-biotin-peroxidase labelled complex, respectively, which were both purchased from Dakopatts A/S (Copenhagen, Denmark). All incubations were carried out for 30 minutes at room temperature, then the specimens were washed in three changes of phosphate buffered saline at $\mathrm{pH} 7.2$ for 15 minutes. The reaction product was developed by the addition of diaminobenzidine and hydrogen peroxide resulting in brown immunoreactive sites. The slides were faintly counterstained with Harris haematoxylin. Finally, the sections were rinsed with distilled water and coverslipped with glycerol. Control slides were treated in an identical manner, except that an irrelevant IgG mouse monoclonal antibody was used in the first step or the primary antibody was omitted.

Cells were counted in five representative microscopic fields. We used an eye piece calibrated grid with $25 \times$ magnification. With this magnification and calibration, we counted the cells present in an area of $0.155 \times 0.155$ $\mathrm{mm}$.

\section{ZYMOGRAPHY}

Seven children with asymptomatic mild to moderate active trachoma ${ }^{2}$ ranging in age from 7 to 16 years (mean age 9.4 years) were included in the study. A $2 \times 2 \mathrm{~mm}$ upper palpebral conjunctival biopsy specimen was obtained from each patient after informed consent. None of the patients was on topical therapy. In addition, seven upper palpebral conjunctival biopsy specimens were obtained from patients in a similar age group undergoing strabismus surgery without obvious inflammation and served as controls.

The conjunctival biopsy specimens were immediately snap frozen in Tissue-Tek optimum cutting temperature (OCT) compound (Miles Laboratories, IN, USA) and maintained at $-80^{\circ} \mathrm{C}$ until use. For gelatin zymography, frozen tissues were thawed and transferred into $50 \mu \mathrm{l}$ of phosphate buffered saline, $\mathrm{pH}$ 7.4, supplemented with $1 \%$ Triton X-100. This preparation was sonicated at $0^{\circ} \mathrm{C}$ for 3 minutes and protein concentrations were determined on a fraction. For each specimen an equivalent amount of $100 \mu \mathrm{g}$ protein was analysed as described by Masure et al..$^{15}$ The localisation of gelatinolytic enzymes and their molecular masses was derived by including protein sizing standards on each gel and on the basis of the known migration of gelatinase $B$ variants (monomer, dimer, and heterodimer with neutrophil gelatinase B associated lipocalin) that were purified by Masure et al..$^{15}$ Briefly, samples were examined by electrophoresis in $7.5 \%$ polyacrylamide gels which had been copolymerised with $0.1 \%$ (W/V) gelatin (Sigma Chemical Company, St Louis, MO, USA). Stacking gels contained 5\% polyacrylamide. Electrophoresis was at $4^{\circ} \mathrm{C}$ for 16 hours at 90 $\mathrm{V}$. The gels were then incubated in washing buffer (50 mM TRIS-HCl, pH 7.5, $10 \mathrm{mM}$ $\mathrm{CaCl}_{2}, 0.02 \%(\mathrm{~W} / \mathrm{V}) \mathrm{NaN}_{3}, 2.5 \%$ (V/V) Triton $\mathrm{X}-100$ ) at room temperature, twice for $20 \mathrm{~min}-$ utes, to remove sodium dodecyl sulphate and overnight in developing buffer (50 mM TRIS$\mathrm{HCl}, \mathrm{pH} 7.5,10 \mathrm{mM} \mathrm{CaCl}_{2}, 0.02 \%$ (W/V) $\mathrm{NaN}_{3}, 1 \%(\mathrm{~V} / \mathrm{V})$ Triton X-100) at $37^{\circ} \mathrm{C}$. The gels were then stained in Coomassie brilliant blue R-250 and destained in methanol/acetic acid. The sites of gelatinase activity appeared as unstained bands on a blue background and were quantified by computerised image analysis through scanning densitometry and 
activities were expressed as arbitrary laboratory scanning units. Densitometry was with a PDI densitometric scanner and the raw data were processed with the Pharmacia Biotech software programs LabScan Utility (Version 2.00) and Image Master ID (Version 2.0). The linear range was between 200 and 7000 scanning units. Quantitation of gelatinase activity by zymography proved to be a sensitive nonisotopic detection method with a sensitivity in the picogram range. ${ }^{16}$

All data are presented as mean (SD). The Mann-Whitney U test was used to analyse the statistical significance of differences between mean values. The differences were considered significant if $\mathrm{p}$ value is $<0.05$.

\section{Results}

IMMUNOLOCALISATION OF GELATINASE B

There was no staining in the negative control slides. In normal conjunctiva, gelatinase B was detected only in polymorphonuclear cells located in the vascular lumens in three specimens (Fig 1(1)). All trachoma specimens showed immunoreactivity with the monoclonal antibody against macrophages CD68 (Fig $1(2)$ ) and the monoclonal antibody against gelatinase $\mathrm{B}$ in the epithelial and stromal inflammatory infiltrate (Fig 1(3)). Gelatinase B was restricted to polymorphonuclear cells and monocytes/macrophages that showed cytoplasmic fine granular staining. The latter cells coexpressed the CD68 marker in serial sections confirming localisation of gelatinase $\mathrm{B}$ in monocytes/macrophages. Figure $2(4 a)$ is stained for gelatinase B, and Figure 2(4b) for macrophages, and it is apparent that nearly all the macrophages of this specimen are positive for gelatinase B. In the stroma most of the positively stained polymorphonuclear cells were still located in the intravascular spaces. In the centre of the lymphoid follicles, the
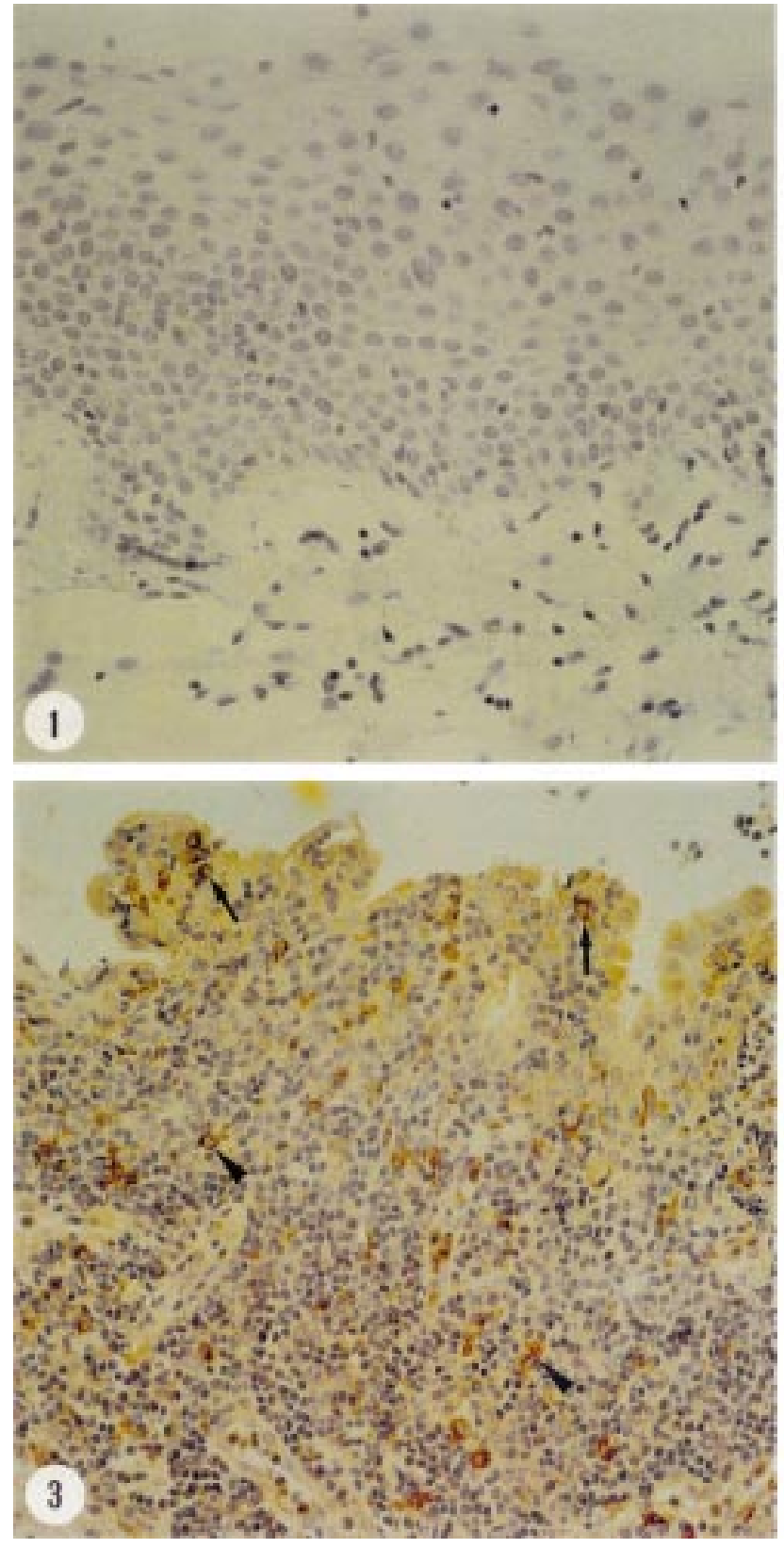

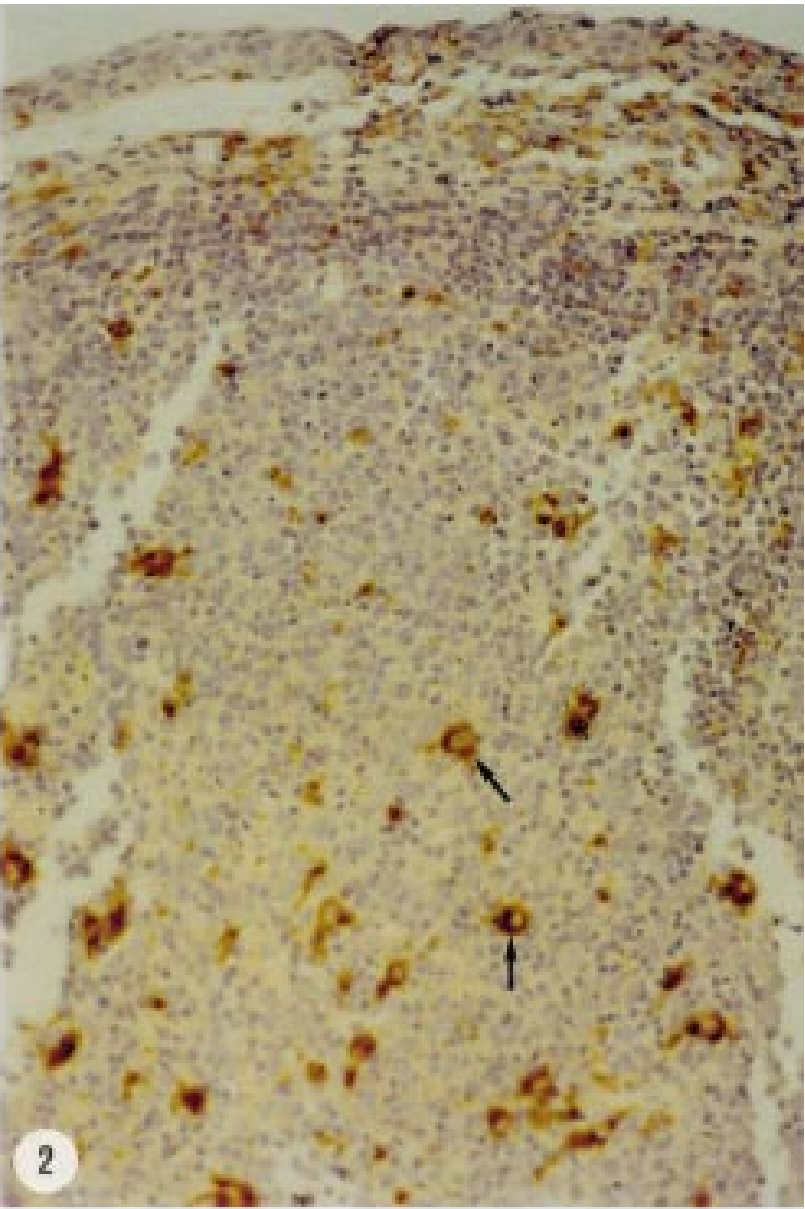

Figure 1 (1) Immunohistochemical staining for gelatinase $B$ of conjunctiva from a normal control subject showing no immunoreactivity (three step avidin-peroxidase conjugated biotin complex; $\times 300$ ). (2) Trachoma. Immunohistochemical staining for the macrophage marker CD68 showing immunoreactivity in the epithelial and stromal

inflammatory infiltrate (arrows) (three step avidin-peroxidase conjugated biotin complex; $\times 300)$. (3) Trachoma. Immunohistochemical staining for gelatinase B showing immunoreactivity in the epithelial (arrows) and stromal (arrowheads) inflammatory infiltrate (three step avidin-peroxidase conjugated biotin complex; $\times 300)$. 
monocytes/macrophages with gelatinase B immunoreactivity were larger and some were multinucleated giant cells (Fig 2(4)). The morphology of these cells varied from round to dendritic (Fig 2(5)).

In five VKC specimens gelatinase $\mathrm{B}$ immunoreactivity was localised in few polymorphonuclear cells and monocytes/macrophages present in the upper stromal inflammatory infiltrate. The majority of polymorphonuclear cells were located in the intravascular spaces. Monocytes/macrophages in VKC specimens were smaller than in trachoma specimens and showed weaker immunoreactivity (Fig 2(6)). The cell counts are presented in Tables 1 and 2. The numbers of gelatinase $B$ positive monocyte/macrophage cells and polymorpho- nuclear cells in trachoma specimens were significantly higher than in VKC specimens.

\section{ZYMOGRAPHY}

Constitutive gelatinase A was detected in six of seven control specimens, and in six of seven trachoma specimens (Fig 3). The difference between the two groups was not statistically significant (control specimens, 210.5 (114.1) scanning units; trachoma specimens, 292.0 (187.0) scanning units, $\mathrm{p}=0.2623$ )

Inducible gelatinase B was detected in all conjunctival biopsy specimens (Fig 3). Gelatinase $B$ values in trachoma specimens were significantly higher than the values found in control specimens (control specimens, 609.3 (395.9) scanning units; trachoma specimens,
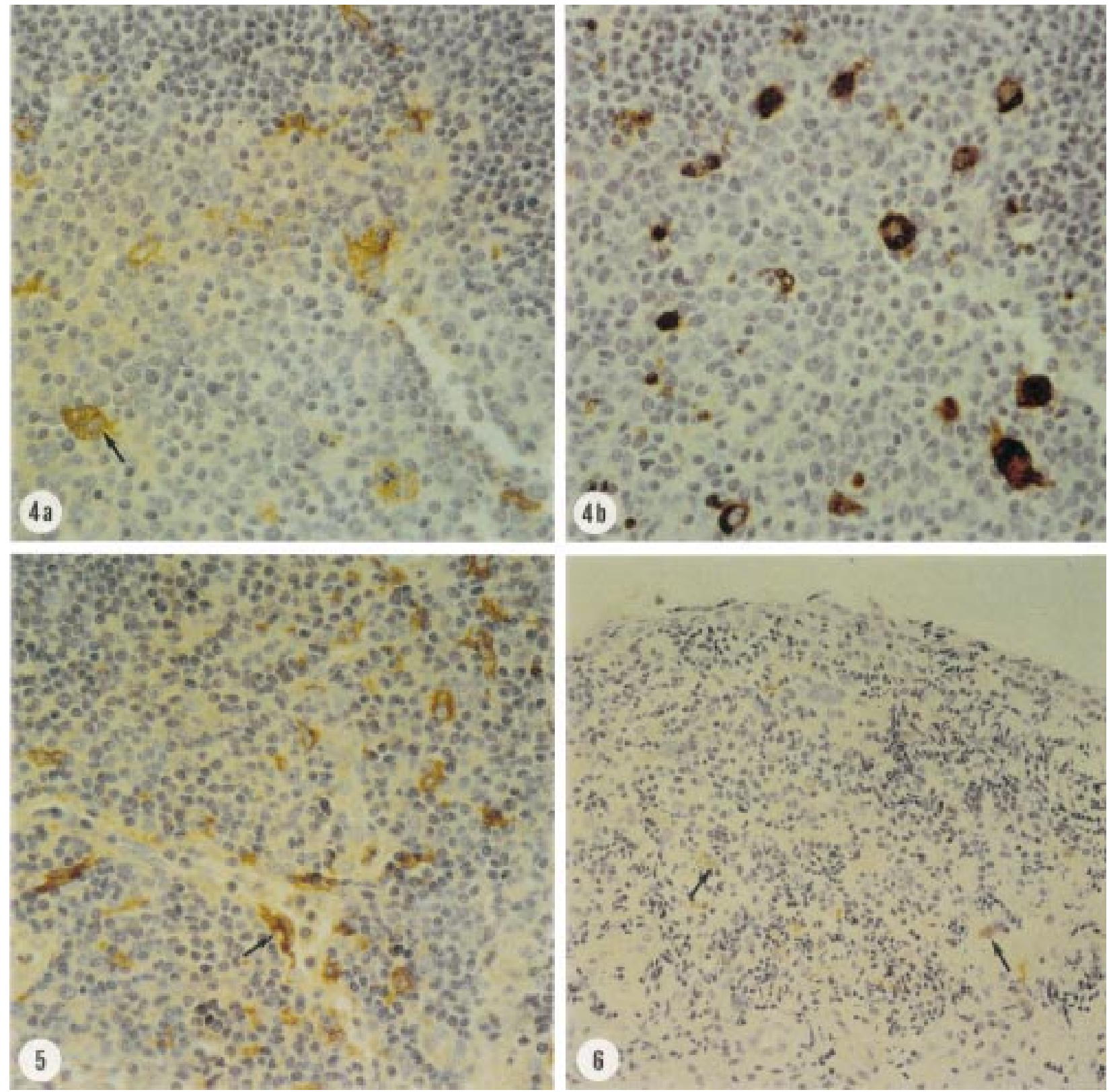

Figure 2 (4)Trachoma. Serial sections illustrating immunohistochemical stainings for gelatinase B (4a) and macrophage marker (CD68) (4b). Nearly all the macrophages are positive for gelatinase B. A multinucleated giant cell expresses gelatinase B (arrow) (three step avidin-peroxidase conjugated biotin complex; $\times 500$ ). (5) Trachoma. Immunohistochemical staining for gelatinase B in monocyte/macrophage cell with dendritic morphology (arrow) (three step avidin-peroxidase conjugated biotin complex; $\times 500)$. (6) Vernal keratoconjunctivitis. Immunohistochemical staining for gelatinase $B$ showing weak immunoreactivity in few monocytes/macrophages in the stromal inflammatory infiltrate (arrows) (three step avidin-peroxidase conjugated biotin complex; $\times 300$ ). 
Table 1 Number of gelatinase B positive cells in trachoma, vernal keratoconjunctivitis (VKC), and control specimens (cells counted in an area of $0.155 \times 0.155 \mathrm{~mm}$ )

\begin{tabular}{lll}
\hline Patient No & $\begin{array}{l}\text { Monocyte/macrophage } \\
\text { cells }\end{array}$ & $\begin{array}{l}\text { Polymorphonuclear } \\
\text { cells }\end{array}$ \\
\hline Trachoma & & \\
1 & 95 & 13 \\
2 & 64 & 48 \\
3 & 42 & 10 \\
4 & 30 & 16 \\
5 & 35 & 37 \\
6 & 48 & 15 \\
VKC & & \\
1 & 12 & 7 \\
2 & 14 & 16 \\
3 & 16 & 8 \\
4 & 0 & 0 \\
5 & 7 & 7 \\
6 & 0 & 0 \\
Control & & \\
1 & 0 & 0 \\
2 & 0 & 8 \\
3 & 0 & 0 \\
4 & 0 & 0 \\
5 & 0 & 10 \\
6 & 0 & 0 \\
7 & 0 & 12 \\
\hline
\end{tabular}

Table 2 Number of gelatinase B positive cells in trachoma and vernal keratoconjunctivitis (VKC) specimens (mean (SD))

\begin{tabular}{lllr}
\hline Cell type & $\begin{array}{l}\text { Trachoma } \\
(n=6)\end{array}$ & $\begin{array}{l}\text { VKC } \\
(n=6)\end{array}$ & p Value \\
\hline $\begin{array}{lllr}\text { Monocyte/macrophage cells } \\
\text { Polymorphonuclear cells }\end{array}$ & $52.3(21.9)$ & $8.2(6.4)$ & $<0.001$ \\
& $23.2(14.2)$ & $6.3(5.4)$ & 0.013 \\
\hline
\end{tabular}

1739.6 (1078.3) scanning units; $p=0.0127$ ). The zymography results are presented in Table 3.

To eliminate the variability inherent in the scanning procedure and possible differences in staining intensity between the zymograms, the ratio of gelatinase $\mathrm{B}$ to gelatinase $\mathrm{A}$ (B:A) was used to quantify the presence of gelatinase $B$. The mean B:A ratio in trachoma specimens was significantly higher than it was in control

A

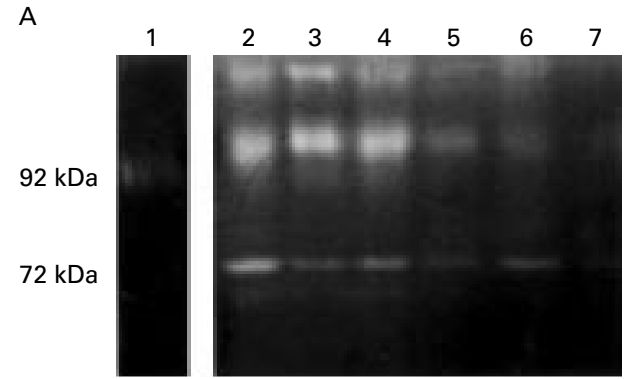

B

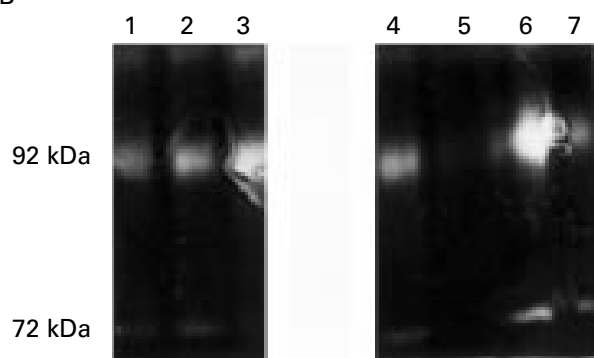

Figure 3 Gelatin zymography of conjunctival biopsy specimens from normal subjects $(A)$, and from patients with active trachoma (B). The zymographies of these samples show the presence of both gelatinase $A(72 \mathrm{kDa})$ and gelatinase $B(92 \mathrm{kDa})$.
Table 3 Gelatinases $A$ and $B$ levels in trachoma and control specimens (scanning units)

\begin{tabular}{lll}
\hline Patient No & Gelatinase $A$ & Gelatinase B \\
\hline Trachoma & & \\
1 & 205 & 1097 \\
2 & 217 & 1462 \\
3 & 137 & 2499 \\
4 & 256 & 1648 \\
5 & ND & 572 \\
6 & 661 & 3778 \\
7 & 276 & 1121 \\
Control & & \\
1 & ND & 629 \\
2 & 411 & 848 \\
3 & 179 & 1110 \\
4 & 238 & 1004 \\
5 & 200 & 371 \\
6 & 171 & 166 \\
7 & 64 & 137 \\
\hline
\end{tabular}

$\mathrm{ND}=$ not detected .

specimens (control specimens, 2.9 (1.9); trachoma specimens, $7.8(5.2) ; \mathrm{p}=0.025)$.

\section{Discussion}

Chronic inflammatory conditions resulting in the restructuring of connective tissue are often characterised by a local accumulation of macrophages. These cells orchestrate connective tissue destruction either directly, by the secretion of elevated levels of matrix metalloproteinases, ${ }^{17}$ or indirectly, by the production of proinflammatory cytokines, including interleukin-1 (IL-1) and tumour necrosis factor- $\alpha$ (TNF- $\alpha){ }^{18}$ In turn, these cytokines have been shown to induce matrix metalloproteinase gene expression in the resident cell population. There is evidence that macrophages are activated during $C$ trachomatis infection. In a previous immunohistochemical study we demonstrated the presence of increased numbers of macrophages in the conjunctival biopsy specimens from patients with active trachoma. These macrophages showed cytoplasmic expression of IL-1 $\alpha$, IL$1 \beta$, TNF- $\alpha$, and platelet derived growth factor. ${ }^{4}$

In the present study, gelatinase A levels did not vary among conjunctival biopsy specimens from control subjects, and those from subjects with active trachoma. Human gelatinase A occurs constitutively in body fluids (serum, synovial fluid, cerebrospinal fluid) and cell culture supernatants. ${ }^{19}$ It is suggested that gelatinase A appears to be involved in some basal extracellular matrix turnover events, whereas gelatinase B appears to be involved in more acutely regulated events. ${ }^{20}$ In normal human and mouse macrophages and human macrophage cell lines, gelatinase A is constitutively produced in small, but detectable, quantities and this production remains at the same level after macrophage stimulation. In contrast, unstimulated macrophages do not produce gelatinase $\mathrm{B}$, but secrete large amounts of this enzyme after appropriate stimulation by, for example, cytokines and endotoxin. ${ }^{1012} 1621$ Zymography indicated an increasing activity of gelatinase B in trachoma specimens. Using immunohistochemistry, we have demonstrated that gelatinase B was specifically localised in macrophages and polymorphonuclear cells present in the inflammatory infiltrate in 
trachoma specimens. Macrophages, monocytes, and neutrophils cells are the main producers of gelatinase B. ${ }^{21}{ }^{22}$ Most of the stromal polymorphonuclear cells were in the intravascular spaces indicating that macrophages were primarily responsible for the production of gelatinase B. Some macrophages were organised into giant cells that stained positively with the anti-gelatinase $\mathrm{B}$ monoclonal antibody. Macrophages synthesise and secrete matrix metalloproteinases which are capable of degrading all macromolecular constituents of the extracellular matrix. ${ }^{17}$ These enzymes appear to function as a proteolytic cascade of which gelatinase $\mathrm{B}$ is a downstream element and whose activation is initiated after that of stromelysin. ${ }^{23}$ The intracellular localisation of gelatinase B in macrophages can be interpreted as evidence of active synthesis of this enzyme because macrophages do not store this metalloproteinase. ${ }^{21}$ In general, the expression of gelatinase B by macrophages in trachoma agrees with immunolocalisation studies in other chronic inflammatory diseases such as interstitial lung diseases, ${ }^{24}$ emphysema, ${ }^{25}$ pulmonary fibrosis, ${ }^{26}$ aneurysmal and occlusive aortic diseases, ${ }^{27}{ }^{28}$ rheumatoid arthritis, ${ }^{29}$ coronary atherosclerotic lesions, ${ }^{30}$ temporal arteritis, ${ }^{31}$ and chronic synovitis. ${ }^{32}$

Chlamydiae are obligate intracellular Gram negative bacteria which cause persistent intracytoplasmic infection of eukaryotic cells. The mechanism by which $C$ trachomatis induces gelatinase $\mathrm{B}$ expression by macrophages has not been determined. The effects of $C$ trachomatis on the synthesis and release of this enzyme may be related to the production of cytokines. $C$ trachomatis is an effective inducer of IL-1 and TNF- $\alpha$ production by monocytes. ${ }^{33} 34$ Whole spleen cells produced TNF- $\alpha$ in vitro in response to murine $C$ trachomatis in a mouse model of pneumonia caused by murine $C$ trachomatis. ${ }^{35}$ IL- $1 \alpha$ and IL- $1 \beta$ mRNA and bioactivity are induced in murine lungs in response to chlamydial infection. ${ }^{36}$ In agreement with these studies we have demonstrated upregulated production of IL- $1 \alpha$, IL$1 \beta$, and TNF- $\alpha$ in the conjunctiva from patients with active trachoma. ${ }^{4} \mathrm{TNF}-\alpha$, and IL-1 $\beta$ selectively upregulate gelatinase $\mathrm{B}$ by macrophages. ${ }^{1637}$ As in all Gram negative bacteria, the outermost monolayer of $C$ trachomatis is composed of lipopolysaccharide (LPS), a complex glycolipid essential for bacterial survival. ${ }^{38}{ }^{39}$ LPS is a potent inducer of the biosynthesis and secretion of gelatinase $B$ in macrophages. ${ }^{16}{ }^{17} 40-42$ Recently, Ingalls and associates $^{34}$ demonstrated that the inflammatory cytokine response to $C$ trachomatis infection is mediated primarily through LPS and can be completely blocked by a specific LPS antagonist. Chlamydial LPS induces mononuclear phagocytes to produce TNF- $\alpha$ and IL- $1 \beta .^{33}{ }^{34}$ Thus it is possible that gelatinase B production by mononuclear cells may be influenced by these cytokines acting through autocrine pathways. However, Saarialho-Kere and associates $^{42}$ have shown that the LPS mediated effects on gelatinase $\mathrm{B}$ production are probably transduced primarily by signalling pathways through the LPS receptor. Although chlamydial LPS has been shown to elicit secretion of proinflammatory cytokines, Ingalls and associates $^{34}$ showed that the potency of chlamydial LPS was 100 -fold less than that elicited by LPS from Neisseria gonorrhoeae or from Salmonella minnesota. According to these investigators, this relatively weak induction of an acute immune response may partially explain the asymptomatic nature of chlamydial infection.

Gelatinase B degrades denatured collagens (gelatin), collagen types IV, V, VII, and X, elastin and fibronectin. ${ }^{44}$ Therefore, expression of gelatinase $\mathrm{B}$ in trachoma may contribute to progressive breakdown of conjunctiva by degrading minor constituents of the extracellular matrix. The degradation of fibrillar collagen types I, II, and III is initiated by collagenases and completed by gelatinase B. The degradation of collagen types IV and V associated with basement membranes permits the extravasation of macrophages into conjunctival tissue. It has been demonstrated that in vitro migration of $\mathrm{T}$ lymphocytes across a basement membrane equivalent is mediated by gelatinase $\mathrm{B}^{45}$ Macrophage gelatinase B might enhance fibroblast migration into conjunctival epithelium by creating breaks in epithelial basement membrane. Since collagen fragments may be chemotactic for monocytes, degradation of collagen by macrophages could further promote monocyte recruitment. ${ }^{46}$ In addition, chronic release of specific collagen fragments in the conjunctiva by gelatinase $\mathrm{B}$ might contribute to selection of autoreactive $\mathrm{T}$ cells and generation of autoimmunity. ${ }^{12}$

In conclusion, the findings reported in this study provide evidence that active synthesis of gelatinase B by macrophages might be involved in matrix degradation and promotion of conjunctival scarring in trachoma. These findings are potentially important from a fundamental standpoint because they suggest a pathogenetic role for gelatinase B in the development of conjunctival scarring. From a practical standpoint, these findings raise the possibility that inhibitors of metalloproteinase activity, and specifically of gelatinase B, might provide a novel form of therapy for prevention of conjunctival scarring in trachoma.

The authors thank Ms Christel Van den Broeck and Ms Ilse Van Aelst for technical assistance, and Ms Connie B Unisa-Marfil for secretarial work.

\footnotetext{
1 Sullivan LJ, Taylor HR. Trachoma. Sem Ophthalmol 1993;8:196-203.

2 Dawson CR, Jones BR, Tarizzo ML. Guide to trachoma conDawson CR, Jones BR, Tarizzo ML. Guide to trachoma con-
trol in programmes for the prevention of blindness. Geneva: World Health Organisation, 1981

3 Abu El-Asrar AM, Van den Oord JJ, Geboes K, et al. Immunopathology of trachomatous conjunctivitis. Br $\mathcal{F}$ Ophthalmol 1989;73:276-82.

$4 \mathrm{Abu}$ El-Asrar AM, Geboes K, Tabbara KF, et al. Immunopathogenesis of conjunctival scarring in trachoma. Eye 1998;12:453-6.

5 Abu El-Asrar AM, Emarah MH, Van den Oord JJ, et al. Conjunctival epithelial cells infected with Chlamydia Ophthalmol 1989;73:399-400.

6 Abu El-Asrar AM, Geboes K, Al-Kharashi SA, et al. Collagen content and types in trachomatous conjunctivitis. Eye 1998;12:735-9.

7 Abu El-Asrar AM, Geboes K, Al-Kharashi SA, et al. An immunohistochemical study of collagens in trachoma and vernal keratoconjunctivitis. Eye 1998;12:1001-6.
} 
8 Woessner JF. Matrix metalloproteinases and their inhibitors in connective tissue remodelling. FASEB 7 1991;5:214554.

9 Matrisian LM. The matrix-degrading metalloproteinases. Bioassays 1992;14:455-63.

10 Opdenakker G, Van Damme J. Cytokines and proteases in invasive processes: molecular similarities between inflammation and cancer. Cytokine 1992;4:251-8.

11 Sato H, Takino T, Okado Y, et al. A matrix metalloproteinase expressed on the surface of invasive tumour cells. Nature 1994;370:61-5.

12 Opdenakker G, Van Damme J. Cytokine-regulated proteases in autoimmune diseases. Immunol Today 1994;15: 103-7.

13 Paemen L, Martens E, Masure S, et al. Monoclonal antibodies specific for natural human neutrophil gelatinase $B$ used for affinity purification, quantitation by two-site B used for affinity purification, quantitation by two-site ELISA and inhibition

14 Cuzner ML, Gveric D, Strand C, et al. The expression of tissue-type plasminogen activator, matrix metalloproteinases and endogenous inhibitors in the central nervous system in multiple sclerosis: comparison of stages in lesio evolution. I Neuropathol Exp Neurol 1996;55:1194-204.

15 Masure S, Proost P, Van Damme J, et al. Purification and identification of $91-\mathrm{kDa}$ neutrophil gelatinase. Release by the activating peptide interleukin-8. Eur $f$ Biochem 1991;198:391-8

16 Van Ranst M, Norga K, Masure S, et al. The cytokineprotease connection: identification of a $96-\mathrm{KD}$ THP-1 gelatinase and regulation by interleukin-1 and cytokine inducers. Cytokine 1991;3:231-9.

17 Welgus HG, Campbell EJ, Cury JD, et al. Neutral metalloproteinases produced by human mononuclear metalloproteinases produced by human mononuclear ing cellular development. F Clin Invest 1990;86:1496-502

18 Murphy G, Reynolds JJ. Extracellular matrix degradation. In: Royce PM, Steinmann B, eds. Connective tissue and it heritable disorders. New York: Wiley-Liss, 1993:287-316.

19 Paemen L, Olsson T, Soderstrom M, et al. Evaluation of gelatinases and IL- 6 in the cerebrospinal fluid of patients with optic neuritis, multiple sclerosis and other inflammatory neurological diseases. Eur f Neurol 1991;1:55-63.

20 Parshley DE, Bradley JMB, Samples JR, et al. Early changes in matrix metalloproteinases and inhibitors after in vitro laser treatment to the trabecular meshwork. Curr Eye Res 1995;14:537-44.

21 Hibbs MS. Expression of $92 \mathrm{KDa}$ phagocyte gelatinase by inflammatory and connective tissue cells. Matrix 1992; suppl 1:51-7.

22 Murphy G, Hembry RM, McGarrity AM, et al. Gelatinase (type IV collagenase) immunolocalization in cells and tissues: use of an antiserum to rabbit bone gelatinase that tissues: use of an antiserum to rabbit bone gelatinase that identifie.

23 Goldberg GI, Strongin A, Collier IE, et al. Interactin of 92-KD type IV collagenase with the tissue inhibitor of metalloproteinases prevents dimerization, complex formation with interstitial collagenase, and activation of the proenzyme with stromelysin. F Biol Chem 1992;267:4583-91.

24 Fukuda Y, Ishizaki M, Kudoh S, et al. Localization of matrix metalloproteinases-1, -2 and -9 and tissue inhibitor of metalloproteinase- 2 in interstitial lung diseases. Lab Invest 1998;78:687-98.

25 Finlay GA, O'Driscoll LR, Russell KJ, et al. Matrix metalloproteinase expression and production by alveolar macrophages in emphysema. Am $\mathcal{F}$ Respir Crit Care Med 1997;156:240-7.

26 Denholm EM, Rollins SM. Aveolar macrophage secretion of a $92-\mathrm{KDa}$ gelatinase in response to bleomycin. Am Physiol 1993;265:L581-3.
27 McMillan WD, Patterson BK, Keen RR, et al. In situ localization and quantification of mRNA for $92-\mathrm{KD}$ type IV collagenase and its inhibitor in aneurysmal, occlusive, and collagenase and its inhibitor in aneurysmal, occlusive, and 44.

28 Thompson RW, Holmes DR, Mertens RA, et al. Production and localization of 92-Kilodalton gelatinase in abdominal aortic aneurysms. An elastolytic metalloproteinase expressed by aneurysm-infiltrating macrophages. F Clin Invest 1995;96:318-26.

29 Tetlow LC, Lees M, Ogata Y, et al. Differential expression of gelatinase B (MMP-9) and stromelysin-1 (MMP-3) by rheumatoid synovial cells in vitro and in vivo. Rheumatol Int 1993;13:53-9.

30 Brown DL, Hibbs MS, Kearney M, et al. Identification of 92-KD gelatinase in human coronary atherosclerotic lesions. Association of active enzyme synthesis with unstable angina. Circulation 1995;91:2125-31.

31 Nikkari ST, Höyhtyä M, Isola J, et al. Macrophages contain Nikkari ST, Hoyhtyä M, Isola J, et al. Macrophages contain
92-Kd gelatinase (MMP-9) at the site of degenerated internal elastic lamina in temporal arteritis. Am f Pathol 1996;149:1427-33.

32 Grillet B, Dequeker J, Paemen L, et al. Gelatinase B in chronic synovitis: immunolocalization with a monoclonal antibody. Br F Rheumatol 1997;36:744-7.

33 Rothermel CD, Schachter J, Lavrich P, et al. Chlamydia trachomatis-induced production of interleukin-1 by human monocytes. Infect Immun 1989;57:2705-11.

34 Ingalls RR, Rice PA, Qureshi N, et al. The inflammatory cytokine response to Chlamydia trachomatis infection is endotoxin mediated. Infect Immun 1995;63:3125-30.

35 Williams DM, Bonewald LF, Roodman GD, et al. Tumor necrosis factor alpha is a cytotoxin induced by murine Chlamydia trachomatis infection. Infect Immun 1989;57. 1351-5.

36 Magee DM, Smith JG, Bleichker CA, et al. Chlamydia trachomatis pneumonia induces in vivo production of
interleukin-1 and -6. Infect Immun 1992;60:1217-20.

37 Saren P, Welgus HG, Kovanen PT. TNF $-\alpha$ and IL-1 $\beta$ selectively induce expression of $92-\mathrm{KDa}$ gelatinase by selectively induce expression of 92-KDa gelatinase

38 Brade L, Holst O, Kosma P, et al. Charaterization of murine monoclonal and murine, rabbit, and human polyclonal antibodies against chlamydial lipopolysaccharide. Infect Immun 1990;58:205-13.

39 Campbell S, Richmond SJ, Yates PS, et al. Lipopolysaccharide in cells infected by Chlamydia trachomatis. Microbiol 1994;140:1995-2002.

40 Xie B, Dong Z, Fidler IJ. Regulatory mechanisms for the expression of type IV collagenases/gelatinases in murine macrophages. F Immunol 1994;152:3637-44.

41 Temblay P, Houde M, Arbour N, et al. Differential effects of PKC inhibitors on gelatinase $B$ and interleukin 6 production in the mouse macrophage. Cytokine 1995;7: $130-6$.

42 Saarialho-Kere UK, Welgus HG, Parks WC. Distinct mechanisms regulate interstitial collagenase and $92-\mathrm{kDa}$ gelatinase expression in human monocytic-like cells exposed to bacterial endotoxin. F Biol Chem 1993;268: 17354-61.

43 Senior RM, Griffin GL, Fliszar CJ, et al. Human 92- and 72-kilodalton type IV collagenases are elastases. f Biol Chem 1991;266:7870-5.

44 Murphy G, Cookett MI, Ward RV, et al. Matrix metalloproteinase degradation of elastin, type IV collagen and proteoglycan. A quantitative comparison of activities of 92 $\mathrm{kDa}$ and $72 \mathrm{kDa}$ gelatinases, stromelysins -1 and -2 and punctuated metalloproteinases (PUMP). Biochem f 1991; 277:277-9.

45 Leppert D, Waubant E, Galardy R, et al. T cell gelatinases mediate basement membrane transmigration in vitro. $\mathcal{F}$ Immunol 1995;154:4379-89.

46 Malone JD, Richards M, Jeffrey JJ. Recruitment of peripheral mononuclear cells by mammalian collagenase digests of type I collagen. Matrix 1991;11:289-95. 